\title{
Two Cytosolic Components of the Human Neutrophil Respiratory Burst Oxidase Translocate to the Plasma Membrane during Cell Activation
}

Robert A. Clark, Bryan D. Volpp, Kevin G. Leidal, and William M. Nauseef

Department of Medicine, University of Iowa College of Medicine and Veterans Administration Medical Center, Iowa City, Iowa 52242

\begin{abstract}
The superoxide-forming respiratory burst oxidase of human neutrophils is composed of membrane-associated catalytic components and cytosolic constituents required for oxidase activation. This study concerns the hypothesis that cytosolic oxidase components translocate to a membrane fraction when neutrophils are stimulated and the oxidase is activated. $A$ polyclonal antiserum that recognizes two discrete cytosolic oxidase components of 47 and $67 \mathrm{kD}$ was used to probe transfer blots of electrophoresed membrane and cytosol fractions of resting and stimulated neutrophils. In contrast to their strictly eytosolic localization in unstimulated cells, both proteins were detected in membrane fractions of neutrophils activated by phorbol esters and other stimuli. This translocation event was a function of stimulus concentration as well as time and temperature of exposure to the stimulus. It was inhibited by concentrations of $\boldsymbol{N}$-ethylmaleimide that blocked superoxide formation but was unaffected by 2-deoxyglucose. There was a correlation between translocation of the cytosolic proteins and activation of the oxidase as determined by superoxide formation. Quantitative analyses suggested that $\sim 10 \%$ of total cellular p47 and p67 became membrane-associated during phorbol ester activation of the oxidase. Analysis of Percoll density gradient fractions indicated that the target membrane for translocation of both proteins was the plasima membrane rather than membranes of either specific or azurophilic granules. In the cell-free oxidase system arachidonate-dependent but membrane-independent precipitation of the cytosolic oxidase proteins was demonstrated. The data show that activation of the respiratory burst oxidase in stimulated human neutrophils is closely associated with translocation of the 47- and 67-kD cytosolic oxidase components to the plasma membrane. We suggest that this translocation event is important in oxidase activation. (J. Clin. Invest. 1990. 85:714-721.) neutropihil - NADPH oxidase • respiratory burst • superoxide • chronic granulomatous disease
\end{abstract}

\section{Introduction}

The microbicidal and cytotoxic activities of polymorphonuclear leukocytes (PMN) are to a large extent dependent on a

Portions of this work were presented at the 1989 Annual Meeting of the Association of American Physicians, Washington, DC and appeared in abstract form (1989. Clin. Res. 37:607A).

Address reprint requests to Dr. Clark, Department of Medicine, University of Iowa, School of Medicine, Iowa City; IA 52242.

Received for publication 6 April 1989 and in revised form 22 September 1989.

J. Clin. Invest.

(C) The American Society for Clinical Investigation, Inc.

0021-9738/90/03/0714/08 \$2.00

Volume 85, March 1990, 714-721 burst of oxidative metabolism which generates superoxide anion, hydrogen peroxide, and other reactive products of oxygen (1-3). The oxidative burst is mediated by an activatable nicotinamide adenine dinucleotide phosphate (NADPH) oxidase present in normal PMN but nonfunctional in cells of patients with the inherited disorder chronic granulomatous disease (CGD) ${ }^{1}(1-9)$. The NADPH oxidase system is composed of several discrete components, some residing in the membrane and others in the cytosol $(2,8-15)$. The membrane-associated components act catalytically to shuttle electrons from cytosolic NADPH to molecular oxygen. The terminal component of this electron transport chain is a low-potential heme protein, cytochrome $b_{558}$, which is a heterodimer composed of a $22-\mathrm{kD} \alpha$ chain and a $91-\mathrm{kDa} \beta$ chain (16-18). In most patients with the classical X-linked variety of CGD, cytochrome $b$ is absent due to an abnormality in the gene encoding its $\beta$ subunit (19-22).

The cytosolic oxidase components are required for activation of the latent membrane oxidase (13-15), although the biochemical events involved in activation are largely unknown. We have recently identified two specific PMN cytosolic proteins required for the generation of an active NADPH oxidase (23). These proteins with molecular mass (by sodium dodecyl sulfate [SDS]-polyacrylamide gel electrophoresis [PAGE]) of $47^{\circ}$ and $67 \mathrm{kD}$ are detected only in the cytosolic fraction of resting PMN and related myeloid cells. The critical functional importance of these two proteins was validated by studies of a subset of CGD patients who exhibit autosomal inheritance, normal membrane content of cytochrome $b_{558}$, and a defect localized to the cytosol in a cell-free oxidase system (24-27). All of these patients studied to date have a complete deficiency of one or the other of the cytosolic oxidase components, deficiency of the $47-\mathrm{kD}$ protein being substantially more prevalent than that of the $67-\mathrm{kD}$ species $(23,27)$. The molecular cloning of cDNAs for both cytosolic proteins has recently been reported (28-32).

Although it is clear that the $47-$ and $67-\mathrm{kD}$ cytosolic proteins ( $\mathrm{p} 47$ and p67, respectively) are essential components of the oxidase system, their specific roles have not yet been defined. In the reconstituted cell-free oxidase system membranes from resting PMN areincubated with cytosol and either arachidonic acid or SDS (10-14). Membrane fractions recovered from such mixtures possess a fully active NADPH oxidase having no further requirement for either cytosol or fatty acid $(13,14,33)$. These observations suggest two potential explanations for the role of the cytosolic factors. They may translocate to the membranes where direct participation in activation or catalysis could take place. Alternatively, they might function

1. Abbreviations used in this paper: CGD, chronic granulomatous disease; DFP, diisopropylfluorophosphate; 2-DOG, 2-deoxy-D-glucose; NEM, $N$-ethylmaleimide; $\mathrm{p} 47$ and $\mathrm{p} 67,47-$ and $67-\mathrm{kD}$ cytosolic oxidase components. 
strictly as signaling moieties, influencing the functional state of the membrane-bound components without becoming directly associated with them. The current studies were designed to test the hypothesis that either one or both of the cytosolic components translocates to the membrane in association with oxidase activation.

\section{Methods}

Neutrophils. Blood was drawn from normal subjects after informed consent was obtained, and neutrophils were purified by sequential Dextran sedimentation, Hypaque-Ficoll differential density centrifugation, and hypotonic lysis of erythrocytes (34). Neutrophils of 98\% purity and viability (trypan blue exclusion) were pretreated with $2 \mathrm{mM}$ diisopropylfluorophosphate (DFP; Sigma Chemical Co., St. Louis, $\mathrm{MO}$ ) at $4^{\circ} \mathrm{C}$ for $20 \mathrm{~min}$, washed, and suspended in phosphate-buffered saline with glucose ( $\mathrm{Na}, \mathrm{Na}$ phosphate buffer, $10 \mathrm{mM}, \mathrm{pH} \mathrm{7.4,} \mathrm{NaCl}$ $140 \mathrm{mM}$, D-glucose $10 \mathrm{mM}$ ) at $5 \times 10^{7} / \mathrm{ml}$ and kept at $4^{\circ} \mathrm{C}$ for not $>1$ $\mathrm{h}$ before use.

Neutrophil activation and fractionation. Neutrophils $\left(3 \times 10^{7}\right.$ cells/ $0.6 \mathrm{ml}$ ) were brought to $37^{\circ} \mathrm{C}$ by preincubation in a water bath for 2 min. An activating agent or control solution was added, the $37^{\circ} \mathrm{C}$ incubation was continued for a specified period, and the samples were then placed in an ice bath (see figure legends for details). The cells were pelleted at $500 \mathrm{~g}$ for $5 \mathrm{~min}$ at $4^{\circ} \mathrm{C}$ and then resuspended in $0.6 \mathrm{ml}$ of relaxation buffer $\left(\mathrm{KCl} 100 \mathrm{mM}, \mathrm{NaCl} 3 \mathrm{mM}, \mathrm{MgCl}_{2} 3.5 \mathrm{mM}\right.$, EGTA $1.25 \mathrm{mM}, 1$,4-piperazine diethane sulfonic acid $10 \mathrm{mM}, \mathrm{pH}$ 7.3) (34). The cells were then disrupted by two 15 -s cycles of sonication at $4^{\circ} \mathrm{C}$ using a microprobe sonicator (Ultrasonics, Inc., Plainview, NY) at maximum power. Unbroken cells and nuclei were pelleted by centrifugation at $500 \mathrm{~g}$ for $5 \mathrm{~min}$ at $4^{\circ} \mathrm{C}$. The supernatant (S1) was then centrifuged at $110,000 \mathrm{~g}$ for $6 \mathrm{~min}$ at $4^{\circ} \mathrm{C}$ in a TL-100 ultracentrifuge with a TLA 100.2 rotor (Beckman Instruments, Inc., Palo Alto, CA). The high-speed supernatant (S2) represented the soluble cytosolic fraction. The pellet (P2) was resuspended in $0.6 \mathrm{ml}$ of relaxation buffer with vigorous mixing and this sample was again centrifuged at 110,000 $g$ for 6 min at $4^{\circ} \mathrm{C}$. The final supernatant (S3) represented a wash fraction. The final pellet $(\mathrm{P} 3)$ representing the membrane fraction was resuspended in $0.6 \mathrm{ml}$ of relaxation buffer.

In a separate series of experiments the cell fractionation technique was modified to permit an assessment of isolated plasma membrane and granule membrane fractions. Neutrophil preparation, stimulation, and sonication were done as above, except for use of a larger number of cells $\left(3 \times 10^{8} / 6 \mathrm{ml}\right)$. One-third of the $S 1$ supernatant $\left(1 \times 10^{8}\right.$ cell equivalents) was processed as above whereas the remaining two-thirds was placed on a discontinuous isotonic Percoll (Pharmacia, Inc., Piscataway, NJ) gradient (34). After centrifugation at $48,000 \mathrm{~g}$ for $15 \mathrm{~min}$ at $4^{\circ} \mathrm{C}$, the fractions containing cytosol and the various membrane organelles were harvested. Membrane fractions were pelleted $(110,000$ $g, 6 \mathrm{~min}, 4^{\circ} \mathrm{C}$ ), washed to remove Percoll and soluble materials as described (34), and resuspended in $200 \mu \mathrm{l}$ of relaxation buffer. Biochemical assays of lactate dehydrogenase, alkaline phosphatase, vitamin $B_{12}$-binding protein, and myeloperoxidase were used as previously described $(13,34)$ for markers of cytosol, plasma membranes, specific granules, and azurophilic granules, respectively. Cytosol harvested from the top of the gradient contained all of the lactate dehydrogenase. The membrane band at a density of $1.026 \mathrm{~g} / \mathrm{ml}$ contained $80 \%$ of the membrane-associated alkaline phosphatase, $6 \%$ of the myeloperoxidase and $<2 \%$ of the vitamin $\mathrm{B}_{12}$-binding protein. The membrane band at a density of $1.084 \mathrm{~g} / \mathrm{ml}$ contained $>95 \%$ of the vitamin $B_{12}$-binding protein, $10 \%$ of the alkaline phosphatase, and $8 \%$ of the myeloperoxidase. The membrane band at a density of $1.135 \mathrm{~g} / \mathrm{ml}$ contained $85 \%$ of the myeloperoxidase, $4 \%$ of the alkaline phosphatase, and $<2 \%$ of the vitamin $B_{12}$-binding protein.

Cell-free system. A cell-free NADPH oxidase system was reconstituted from subcellular organelles of resting human neutrophils as previously described (13). Briefly, DFP-treated neutrophils were disrupted by nitrogen cavitation in relaxation buffer plus ATP $1 \mathrm{mM}$ and subcellular fractionation was done on Percoll density gradients. The complete cell-free system was composed of cytosol, membrane fractions (plasma membrane and/or specific granules), and arachidonic acid. After mixing the components at $4^{\circ} \mathrm{C}$, membrane and soluble (S) fractions were prepared by centrifugation at $110,000 \mathrm{~g}$ for $6 \mathrm{~min}$ at $4^{\circ} \mathrm{C}$. The membrane pellet was washed by resuspension in relaxation buffer and after a second centrifugation at $110,000 \mathrm{~g}$ for $6 \mathrm{~min}$ the pelleted membranes $(\mathrm{P})$ were resuspended in relaxation buffer.

Superoxide assay. Superoxide production was determined in a continuous kinetic assay as the superoxide dismutase-inhibitable reduction of ferricytochrome $c$ (13).

Electrophoresis and immunoblotting. Fractions from activated neutrophils or the cell-free system were subjected to SDS-PAGE, the proteins were blotted to nitrocellulose, and the blots were probed with B-1 antiserum as reported (23). This serum is a polyclonal rabbit antiserum prepared against GTP-agarose-purified normal PMN cytosol; it recognizes two predominant proteins of 47 and $67 \mathrm{kD}$ restricted to the cytosol fraction of neutrophils and related myeloid cells. Immunoreactive proteins in the blots were detected with ${ }^{125} \mathrm{I}$-protein $\mathrm{A}$ and autoradiography. The autoradiographs shown in the figures are representative of at least three separate experiments.

Two methods were used for quantitative assessment of the intensity of the bands observed in the autoradiographs. Densitometry was performed on either the developed $x$-ray film or a positive photographic print using a scanning densitometer (model CS-930, Shimadzu, Kyoto, Japan) kindly made available by Dr. T. A. Koerner, University of Iowa. The relative values obtained for the area under the curve for the individual bands were compared. Alternatively, ${ }^{125}$ I radioactivity (from ${ }^{125}$ I-protein A) in the bands was determined, using the autoradiograph as a template for excising the appropriate piece of nitrocellulose from the blot. The nitrocellulose pieces were placed in a gamma scintillation counter (Beckman Instruments, Inc.) for determination of ${ }^{125} I$ counts per minute. Background counts per minute detected in an appropriately sized piece of nitrocellulose from an empty lane of the blot was subtracted from each experimental value. The assay was linear over the range used. The total amount of either p47 or p67 detected in all fractions was used as an internal standard and the data were expressed as percent translocation (i.e., the counts per minute in the pertinent band of the $\mathbf{P} 3$ fraction as a percentage of total counts per minute for the same molecular mass region of $\mathbf{S 2}+\mathbf{S 3}+\mathrm{P} 3$ ).

Materials. Arachidonic acid and other fatty acids were from $\mathrm{Nu}-$ Chek Prep., Inc. (Elysian, MN) and were dissolved in ethanol as described (13). Adenine and guanine nucleotides, phorbol myristate acetate (PMA), formylmethionyleucylphenylalanine (FMLP), EGTA and 2-deoxy-D-glucose (2-DOG) were obtained from Sigma Chemical Co. (St. Louis, MO). PMA and FMLP were dissolved in dimethyl sulfoxide (DMSO; Fisher Scientific Co., Fair Lawn, NJ) at $2.5 \mathrm{mg} / \mathrm{ml}$ and $1 \mathrm{mM}$, respectively. $N$-ethylmaleimide (NEM) and 1,4-piperazine diethane sulfonic acid were from Fisher Scientific Co.

\section{Results}

Translocation of $p 47$ and $p 67$ in stimulated PMN. In our previous studies p47 and p67 were found only in the cytosol fraction of unstimulated PMN (23). The same was true of control PMN incubated at $37^{\circ} \mathrm{C}$ with DMSO (Fig. 1). In contrast, incubation with PMA (in DMSO) resulted in partial translocation of both $p 47$ and p67 to the membrane fraction (P3) as a function of the concentration of phorbol ester (Fig. 1). In parallel studies of superoxide formation by PMA-stimulated PMN, a qualitative association between translocation and rate of superoxide formation was noted (see Fig. 1 legend). The membrane fractions from stimulated but not control PMN exhibited NADPH-dependent superoxide formation as previously described $(1,4-8)$. The amount of each protein that 

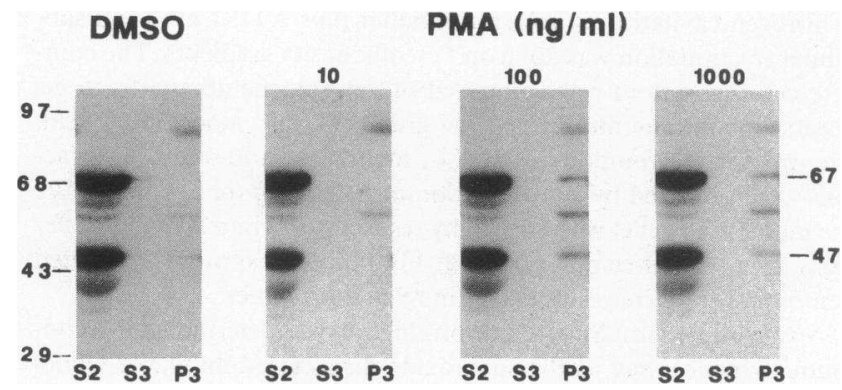

Figure 1. Effect of PMA on the subcellular distribution of $\mathrm{p} 47$ and p67. PMN were incubated with the indicated concentrations of PMA or with $0.004 \%$ DMSO (solvent control) for $3 \mathrm{~min}$ at $37^{\circ} \mathrm{C}$. The cells were then sonicated and fractionated (see Methods). Each fraction (S2, cytosol; S3, membrane wash; P3, membranes) in an aliquot equivalent to $3.75 \times 10^{6}$ starting cells was mixed with SDS-sample buffer, heated in a boiling water bath for $1 \mathrm{~min}$, and run on a 9\% polyacrylamide gel (23). Proteins were electroblotted to nitrocellulose paper which was blocked, probed with B-1 antiserum (1:200), washed, exposed to ${ }^{125} \mathrm{I}$-protein $\mathrm{A}$, and washed again. Labeled protein bands were visualized by autoradiography. The locations of the 47- and 67-kD bands and molecular mass standards are indicated. Densitometry indicated relative intensities (compared with the response to PMA $100 \mathrm{ng} / \mathrm{ml}$ set at $100 \%$ ) for DMSO and the three increasing concentrations of PMA as follows: p47-7, 0, 100, and 21, respectively; p $67-0,0,100$, and 91 , respectively. In parallel assays of the rate of superoxide formation $3 \mathrm{~min}$ after stimulation, relative rates (compared with the response to PMA $100 \mathrm{ng} / \mathrm{ml}$ set at $100 \%$ ) for DMSO and the three increasing concentrations of PMA were 0 , 0,100 , and 89 , respectively. The $100 \%$ value was generally $10-20$ $\mathrm{nmol} / \mathrm{min}$ per $2 \times 10^{6} \mathrm{PMN}$. The reason for the lack of response at 3 min to PMA $10 \mathrm{ng} / \mathrm{ml}$ was that this low concentration of PMA was associated with an increased lag time (about $3 \mathrm{~min}$ in this experiment).

became membrane-associated was a relatively small proportion of that present in cytosol. Thus a stimulus-dependent decrease in the intensity of the 47- and 67-kD bands in cytosol was not detected. The association of the two proteins with the membrane appeared to be quite firm since neither protein could be detected in the S3 wash fraction (Fig. 1). Moreover, the addition of $150 \mathrm{mM} \mathrm{NaCl}$ to the wash buffer resulted in only slight dissociation of either protein from the membranes of PMA-stimulated PMN (data not shown).

As previously described, B-1 is a polyclonal and polyspecific antibody that selectively recognizes p47 and p67 but exhibits additional minor specificities (23). The bands detected in the S2 lanes of Fig. 1 at $\sim 40,55$, and $60 \mathrm{kD}$ are of uncertain identity. Interestingly, the $55-\mathrm{kD}$ protein was also present in the membrane fractions (P3) and, like p47 and p67, exhibited stimulus-dependent translocation to the membrane. The 84-kD band detected in membrane fractions of both resting and stimulated cells (Fig. 1) has been previously shown to be a component of the specific granules (23).

Kinetic and quantitative analysis of translocation. An examination of the time course of protein translocation in PMA-stimulated PMN indicated the earliest detectable change from the zero time sample at $\sim 1$ min after PMA addition (Fig. 2). Thereafter, the intensity of the $47-$ and $67-\mathrm{kD}$ signals in the membrane fraction increased steadily through $10 \mathrm{~min}$. In the continuous superoxide assay under analogous conditions the lag time was $\sim 1 \mathrm{~min}$ as previously reported (35). The kinetic pattern of superoxide formation paralleled the ex-

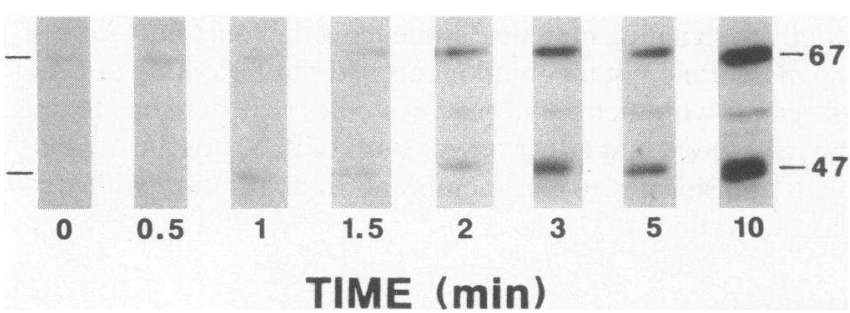

Figure 2. Time course of translocation of p47 and p67 to the membrane fraction. The protocol was the same as in Fig. 1 except that all PMN samples contained PMA $100 \mathrm{ng} / \mathrm{ml}$ and the time of exposure of PMN to PMA at $37^{\circ} \mathrm{C}$ was varied as indicated. Only the membrane fractions (P3) are shown. Densitometry indicated relative intensities (compared with the response at $5 \mathrm{~min}$ set at 100\%) for the eight increasing times shown were as follows: p47-0, 0, 5, 2, 7, 142, 100 , and 506, respectively; p67-1, 2, 2, 1, 33, 159, 100, and 395, respectively. In parallel assays of the rate of superoxide formation the relative rates (expressed as in Fig. 1 with the maximum value [5 min] set at $100 \%$ ) for the eight increasing times shown were $0,0,3,6,31$, 84,100 , and $58 \%$, respectively.

tent of protein translocation (see Fig. 2 legend). However, the rate of superoxide formation tapered off between 5 and $10 \mathrm{~min}$ while translocation continued.

A more quantitative assessment of the extent and kinetics of translocation of p47 and p67 in PMA-stimulated PMN was carried out using ${ }^{125} \mathrm{I}$-protein $\mathrm{A}$ radioactivity in excised bands from the nitrocellulose blot (Fig. 3). In each of three separate experiments the kinetics of p47 and p67 translocation and superoxide formation were similar. Lag times varied from 0.5 to $1 \mathrm{~min}$ and substantial translocation of both proteins was consistently detected by the time maximum rates of superoxide formation were achieved. The maximum extent of translocation (as a percent of total cellular content of $\mathrm{p} 47$ or $\mathrm{p} 67$ ) observed within the first $5 \mathrm{~min}$ varied over a range of 9.2-12.5\% for $\mathrm{p} 47$ and $7.3-7.9 \%$ for $\mathrm{p} 67$.

Effects of temperature, various stimuli, and inhibitors. A clear-cut temperature dependence of protein translocation was

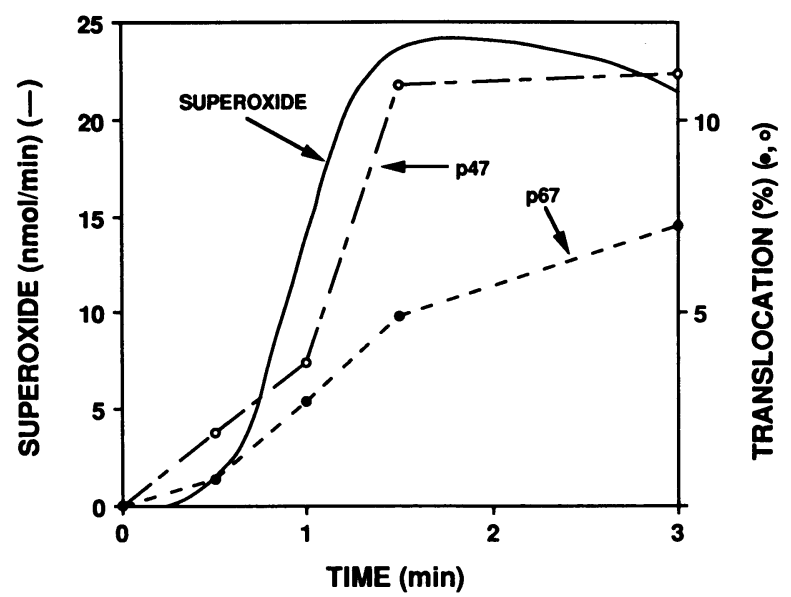

Figure 3. Quantitative kinetics of superoxide formation and translocation of p47 and p67. The protocol was the same as in Fig. 2 except that translocation was quantitated by counting ${ }^{125} \mathrm{I}$-protein A radioactivity in excised bands from the nitrocellulose blots. Data for percent translocation of p47 (o) and p67 (•) and for superoxide formation are from a single experiment representative of a total of three. 
apparent (Fig. 4). Compared with a $37^{\circ} \mathrm{C}$ sample, there was considerably less, but still substantial translocation at $22^{\circ} \mathrm{C}$, a great deal less at $16^{\circ} \mathrm{C}$, and very little at $4^{\circ} \mathrm{C}$. There was a correlation between the effects of temperature on protein translocation and superoxide formation (see Fig. 4 legend).

We next assessed whether activating agents other than phorbol esters caused translocation of the $47-$ and $67-\mathrm{kD}$ proteins (Fig. 5). An optimal concentration of SDS induced substantial translocation of both proteins. FMLP, a weaker stimulator of the oxidative burst than PMA, caused only slight, though detectable protein translocation. Two agents known to inhibit the oxidative burst were examined for their effect on PMA-induced protein translocation. On the one hand, NEM at $100 \mu \mathrm{M}$ completely blocked both translocation and superoxide formation (Fig. 6). At $10 \mu \mathrm{M}$ NEM caused partial inhibition of translocation (data not shown) and $77 \%$ inhibition of superoxide formation (mean, $n=3$ ). On the other hand, concentrations of 2-DOG that substantially inhibited superoxide formation had no detectable effect on translocation of either protein.

Specificity of translocation to plasma membranes. In the foregoing studies membrane samples (P3) contained a mixture of plasma membrane vesicles and granules, and it was therefore not possible to determine which membranes were the target for translocated p47 and p67. Thus, we fractionated resting and PMA-stimulated PMN on Percoll density gradients and analyzed membrane fractions of different densities. Cytosol and three membrane fractions enriched in plasma membranes, specific granules, and azurophilic granules were obtained as documented in Methods. Under the incubation conditions used (PMA $100 \mathrm{ng} / \mathrm{ml}, 37^{\circ} \mathrm{C}, 5 \mathrm{~min}$ ), the extent of release of vitamin $B_{12}$-binding protein was $41-47 \%$ and that of myeloperoxidase was $8-12 \%$. NADPH-dependent superoxide formation was detected only in the plasma membraneenriched fraction of stimulated but not control PMN. Cytosol and membrane fractions from Percoll gradients as well as parallel P3/S2 fractions were analyzed by immunoblotting (Fig. 7). As before, there was translocation of both p47 and p67 which were detected in the P3 fraction of PMA-stimulated cells. In the Percoll gradient fractions translocation of both proteins to the plasma membrane was demonstrated. Selectivity for this membrane fraction was striking in that no $\mathrm{p} 47$ or p67 was detected in either the specific granule or azurophilic

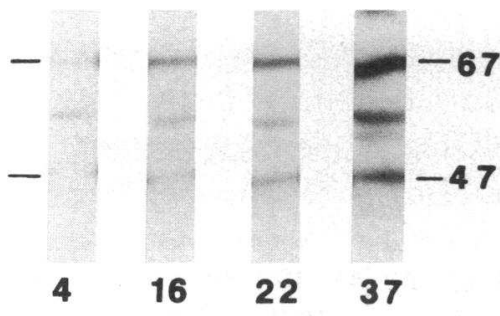

TEMPERATURE $\left({ }^{\circ} \mathrm{C}\right)$ the membrane fractions (P3) are shown. Densitometry indicated relative intensities (compared with the response at $37^{\circ} \mathrm{C}$ set at $100 \%$ ) for the four increasing temperatures as follows: p47-5, 14, 28, and 100 , respectively; p67-3,18, 31, and 100 , respectively. In parallel assays of the rate of superoxide formation the relative rates (expressed as in Fig. 1 with the $37^{\circ} \mathrm{C}$ value set at $100 \%$ ) for the four increasing temperatures were $0,0,42$, and $100 \%$ respectively (means, $n=3$ ).

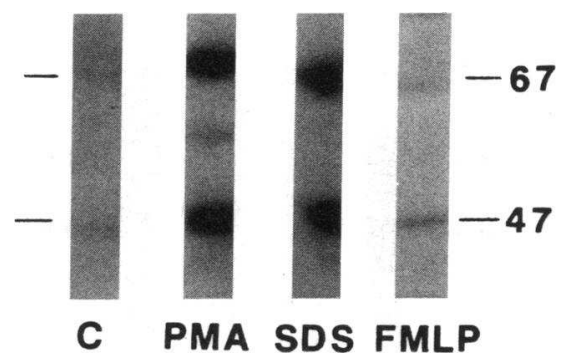

Figure 5. Effect of different stimuli on translocation of $p 47$ and $p 67$ to the membrane fraction. The protocol was the same as in Fig. 1 except that PMN samples were incubated for $5 \mathrm{~min}$ at $37^{\circ} \mathrm{C}$ with no stimulus, PMA $85 \mathrm{ng} / \mathrm{ml}$, SDS $129 \mu \mathrm{M}$, or FMLP $286 \mathrm{nM}$ as indicated. Only the membrane fractions (P3) are shown. Densitometry indicated relative intensities (compared with the response to PMA set at $100 \%$ ) for the four conditions as follows: $p 47-1,100,89$, and 4 , respectively; $\mathrm{p} 67-0,100,103$, and 1 , respectively. In parallel assays of the rate of superoxide formation the relative rates (expressed as in Fig. 1 with the PMA value set at $100 \%$ ) for the four conditions were $0,100,114$, and $35 \%$, respectively (means, $n=3$ ).

granule fraction even though more material was loaded on the gel for granule fractions than for plasma membrane. The 84-kD, specific-granule protein detected by the antiserum was observed in P3, in specific granules, and to some degree in the plasma membrane fraction of stimulated but not control cells, the latter presumably a reflection of the membrane fusion accompanying degranulation.

Cell-free oxidase system. Finally, we examined the behavior of p47 and p67 in the reconstituted cell-free oxidase system (Fig. 8). As expected both proteins were restricted to a cytosolic location in the starting fractions from unstimulated PMN. When mixtures of cytosol and membrane fractions were incubated with arachidonic acid under conditions that maximize oxidase activation, a large portion of both $\mathrm{p} 47$ and $\mathrm{p} 67$ became associated with the membrane fraction. This change in protein distribution did not occur when arachidonic acid was replaced by its solubilizing agent ethanol. However, the appearance of the two proteins in the insoluble (pellet) fraction after ultracentrifugation did not require the presence of membranes in the incubation mixture (Fig. 8). The wash fractions in samples
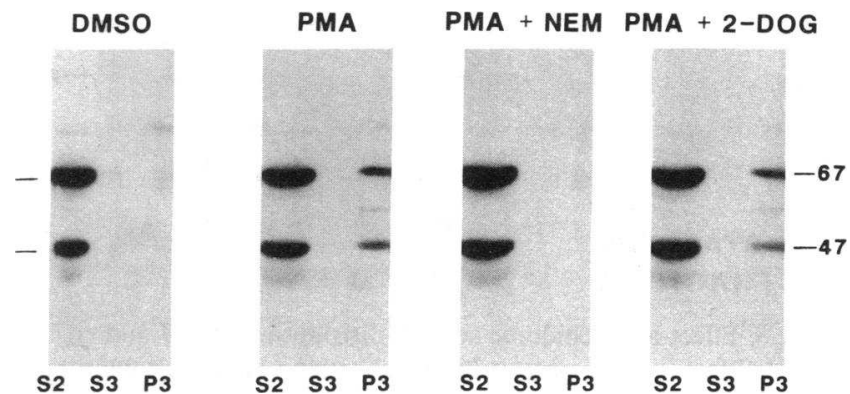

Figure 6. Effect of NEM and 2-DOG on translocation of p47 and p67 to the membrane fraction. The protocol was the same as in Fig. 1 except that PMN samples were incubated for $5 \mathrm{~min}$ at $37^{\circ} \mathrm{C}$ with no stimulus or PMA $100 \mathrm{ng} / \mathrm{ml}$. Where indicated NEM $100 \mu \mathrm{M}$ or 2-DOG $30 \mathrm{mM}$ was present during stimulation. All three fractions (S2, S3, P3) are shown. In parallel assays of the rate of superoxide formation NEM and 2-DOG in the concentrations shown inhibited the response to PMA by $100 \%$ and $46 \%$, respectively (means, $n=3$ ). 


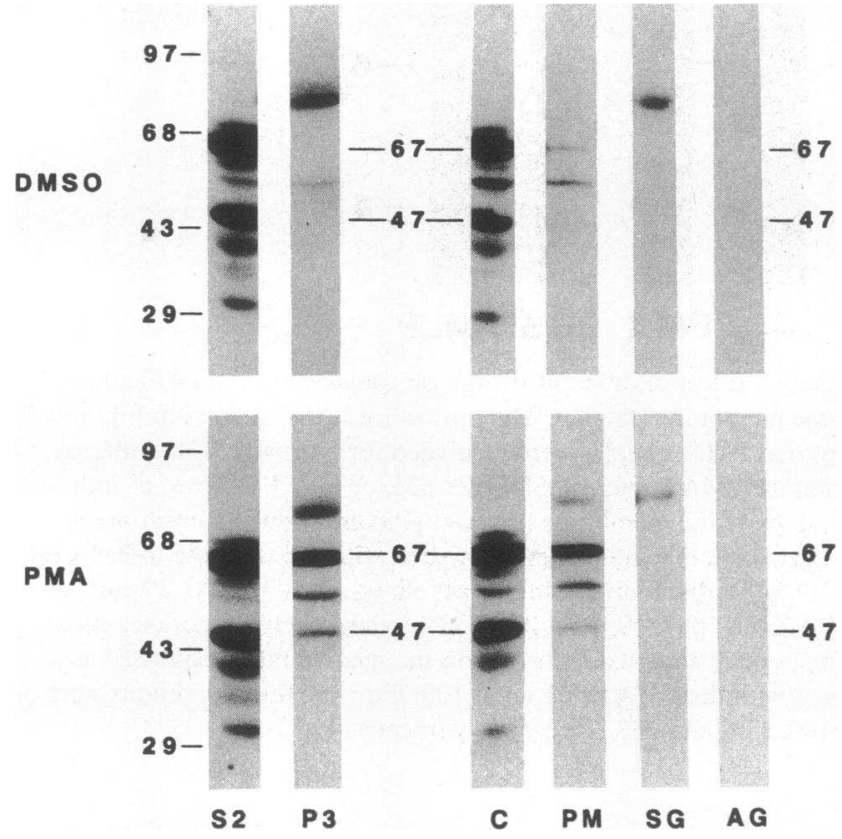

Figure 7. Analysis of membrane subpopulations for translocated $\mathrm{p} 47$ and p67. Control (DMSO) and stimulated (PMA, $100 \mathrm{ng} / \mathrm{ml}, 37^{\circ} \mathrm{C}$, $5 \mathrm{~min}$ ) PMN were fractionated in parallel by the centrifugation method as in Fig. 1 and the Percoll density-gradient method. Fractions were analyzed by SDS-PAGE and immunoblotting as in Fig. 1. Lanes contained fractions $\mathrm{S} 2$ and $\mathrm{P} 3$ from the centrifugation method and cytosol (C), plasma membrane (PM), specific granules (SG), and azurophilic granules (AG) from the Percoll gradient method. The quantities of PM, SG, and AG were standardized with reference to the $\mathrm{P} 3$ fraction based on content of alkaline phosphatase, vitamin $B_{12}$-binding protein and myeloperoxidase, respectively. The amounts loaded per lane (in cell equivalents $\times 10^{6}$ ) were 4 for $S 2, P 3$, and $C$; 6 for PM; and 8 for SG and AG. Note that in the Percoll membrane fractions the unequal loads were biased against $P M$ and in favor of SG and AG. The locations of the 47- and 67-kD bands and molecular mass markers are indicated.

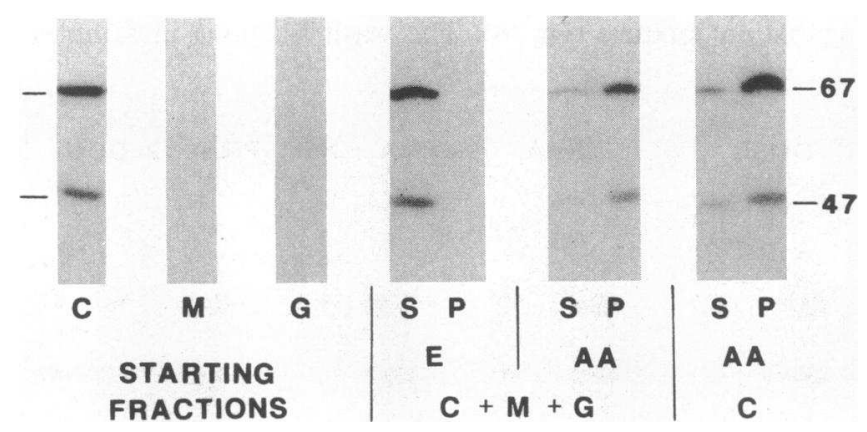

Figure 8. Effect of arachidonic acid on distribution of p47 and p67 in the cell-free oxidase system. Electrophoresis and immunoblotting were done as in Fig. 1. Lanes at the left marked $C, M$, and $G$ contained $5 \times 10^{6}$ cell equivalents of starting fractions of PMN cytosol, plasma membranes, and specific granules, respectively (13). Reaction mixtures for the other lanes contained $20 \times 10^{6}$ cell equivalents of cytosol, plasma membranes, and specific granules or cytosol alone plus either $1.4 \%$ ethanol $(E)$ (solvent control) or $73 \mathrm{nmol}$ of arachidonic acid $(A A)$. After mixing the components soluble $(S)$ and pellet $(P)$ fractions were separated (see Methods) and $5 \times 10^{6}$ cell equivalents of each run on the gel. with or without membranes contained little or no $\mathrm{p} 47$ or $\mathrm{p} 67$. In a system composed of cytosol without membranes, several different fatty acids (arachidonic acid, SDS, oleic acid, and linolenic acid) were able to convert a portion of the 47- and $67-\mathrm{kD}$ proteins to an insoluble form (Figure 9). Each of the fatty acids studied was active in the cell-free NADPH oxidase system, although in each case both cytosol and membrane fractions were essential for superoxide generation.

\section{Discussion}

The critical microbicidal role of the neutrophil respiratory burst is clearly illustrated by the severe problems with recurrent infections observed in patients with CGD $(1-3,6)$. The enzymatic system responsible for the burst has been characterized as a multicomponent oxidase that transports electrons from NADPH to oxygen (1-8). The dormant oxidase in resting PMN is activated during phagocytosis or on exposure to various soluble mediators. Classically, the oxidase has been considered to be a membrane-bound enzyme system based on its segregation with membrane fractions of activated neutrophils (1, 4-8). However, an activatable cell-free oxidase system composed of subcellular organelles from resting cells has permitted a clear demonstration of roles for cytosolic as well as membrane components (10-15). Current experimental evidence indicates that cytosolic components are involved in activation of a membrane-associated enzyme (13-15).

The best characterized membrane oxidase component is cytochrome $b_{558}$, although flavoprotein and quinone participation have also received attention (1-8). Cytosolic components include proteins of 47 and $67 \mathrm{kD}$, both of which are recognized by a polyclonal polyspecific antiserum (B-1) prepared against partially purified PMN cytosol (23). Cytochrome $b_{558}$ is generally absent from patients with classical X-linked CGD, whereas either $\mathrm{p} 47$ or $\mathrm{p} 67$ is missing from CGD patients with autosomal inheritance, normal cytochrome $b_{558}$, and a cytosolic defect in the cell-free oxidase system $(6,7,9,20-27)$.

The mechanism by which the cytosolic components participate in oxidase activation is unknown. The question we have addressed is whether the 47- and 67- $\mathrm{kD}$ components become associated with membranes during activation of the intact

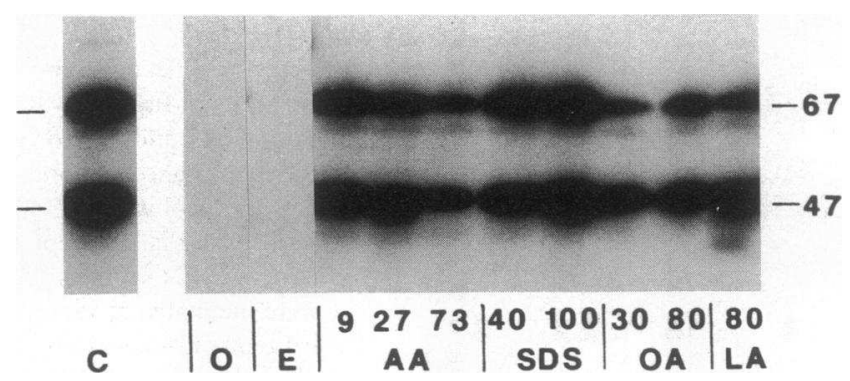

Figure 9. Effect of various fatty acids on the sedimentation of p47 and p67 in isolated cytosol. The lane at the left marked $C$ contained $5 \times 10^{6}$ cell equivalents of starting PMN cytosol. Reaction mixtures for the other lanes contained $20 \times 10^{6}$ cell equivalents of cytosol only $(O)$ or plus $1.4 \%$ ethanol $(E)$ or varied amounts of fatty acids as follows: arachidonic acid $(A A)$ 9, 27, or $73 \mathrm{nmol}$; SDS 40 or 100 nmol; oleic acid $(O A) 30$ or $80 \mathrm{nmol}$; linolenic acid $(L A) 80 \mathrm{nmol}$. Samples were processed as in Fig. 8 but only the pellet (P) fractions are shown. 
neutrophil. The data show clearly that both cytosolic components translocate to a membrane fraction in association with oxidase activation. This translocation event was dependent on stimulus concentration as well as time and temperature of exposure to stimulus. It was observed to varied degrees with several different stimuli. Although FMLP is a less potent respiratory burst stimulus than PMA, its ability to induce translocation was disproportionately low. This raises the possibility of both quantitative and qualitative differences in the translocation process induced by various stimuli. For example, p47 and p67 translocated by FMLP may be less avidly associated with the membrane.

There was a correlation between protein translocation and activation of superoxide formation under the various experimental conditions. NEM inhibited translocation in concentrations that also block superoxide formation. Although the mechanism of inhibition by NEM is unknown, its effect is on oxidase activation in both the intact PMN and the cell-free system and not on expression of activity by the activated oxidase $(36,37)$. The inhibitory effect of 2-DOG on activation of the intact PMN is presumed to be related to a block in glucose utilization $(37,38)$. It has no effect on activation in the cell-free system (Clark, R. A., and K. G. Leidal, unpublished observation). Thus 2-DOG does not directly affect the interaction of oxidase components, in keeping with our finding that it does not block translocation of the cytosolic components to the membrane.

Quantitative analyses of immunoblots suggested that under our experimental conditions only $\sim 10 \%$ of the total cytosolic reservoir of p47 and p67 becomes firmly associated with the membrane. Our analysis may underestimate the amount of translocated protein because of the relatively short ultracentrifugation used to isolate the membrane fraction (6 $\mathrm{min}$ ) and the possibility that loosely associated components may be disrupted during sonication and subcellular fractionation. Moreover, the sigmoidal nature of the cytosol dose-response curve in the cell-free oxidase system $(13,15)$ suggests that once a threshold is reached the extent of oxidase activation could be very steep with respect to translocated cytosolic components.

Regarding the kinetics of oxidase activation as reflected by superoxide formation, there was a close parallel with protein translocation during the early phases encompassing the lag time (0-1 $\mathrm{min})$ and increase to maximum rates (1-5 $\mathrm{min})$. The subsequent gradual decrease in superoxide formation while protein translocation continued (5-10 $\mathrm{min}$ ) suggests that down-regulation of the activated oxidase is not the result of a cessation of translocation but depends on other superimposed events (e.g., feedback inactivation by reactive products of oxygen metabolism [39-41]).

By examining Percoll density-gradient fractions, we showed that the translocated p47 and p67 are associated with plasma membranes and not with the membranes of specific or azurophilic granules. This selective localization is in keeping with the plasma membrane or phagocytic vacuole (i.e., invaginated plasma membrane) site of action of the activated oxidase. In resting $\mathrm{PMN}$, a substantial portion of the cytochrome $b_{558}$ and the activatable oxidase is localized in the membrane of specific granules, but these components move to the plasma membrane during stimulus-induced degranulation (i.e., fusion of granule membranes with plasma membranes) $(13,34)$. Our current data suggest that these granule-associated oxidase components can only be involved in membrane translocation of the cytosolic components after degranulation.

We further examined the translocation events detected in stimulated neutrophils using the reconstituted cell-free NADPH oxidase system with cytosol, membranes, and arachidonic acid. Under the standard conditions for activation of the latent membrane oxidase, both p47 and p67 were detected in the membrane fraction. However, these proteins were also found in an insoluble ultracentrifuge fraction in the absence of membranes suggesting that the formation of fatty acid micelles promoted the nonspecific precipitation of cytosolic proteins. Fatty acids other than arachidonate also precipitated the cytosolic proteins. The implications of these data in the cell-free system are uncertain. Although specific association of cytosolic oxidase components with membranes cannot be claimed, it is possible that the change in physical properties of cytosolic proteins incorporated into fatty acid micelles influences their ability to interact with proteins in the phospholipid bilayer of the cell membrane in a manner which favors the association of cytosolic and membrane oxidase components.

The demonstration that $\mathrm{p} 47$ and p67 in stimulated PMN translocate to the membrane during oxidase activation raises interesting questions about their functional roles. For example, it is now tenable to consider that one or both of these proteins is involved as a catalytic component in the direct link of electron transport between NADPH and oxygen. A proximal location in the sequence would have to be assigned given the evidence that cytochrome $b_{558}$ is the terminal component $(2,4,5-8)$. For example, the NADPH-binding site could reside in one of the cytosolic components. Both the 47- and 67-kD proteins have an affinity for 2 ', $5^{\prime}$-ADP, a property suggestive of NADPH-binding capacity $(23,42)$. A protein of $66-68 \mathrm{kD}$ has been detected in a highly purified oxidase preparation from stimulated neutrophils $(43,44)$, but its relationship to the cytosolic component of similar size is unknown. The use of the 2,3-dialdehyde derivative of NADPH as an affinity probe of the oxidase has identified a similar membrane component, but it is present in membranes of both resting and stimulated $\operatorname{PMN}(45,46)$. The inhibitory effect of the dialdehyde acting as a competitive substrate is directed at a cytosolic protein of undetermined $M_{\mathrm{r}}$ (46).

The 47-kD cytosolic component is a candidate for the phosphoprotein of similar size that undergoes stimulus-dependent phosphorylation in normal but not CGD cells (47-49) and in cell-free systems reconstituted with normal but not autosomal CGD cytosol (25). Using $\left[\gamma-{ }^{32} P\right] A T P$ labeling, the 47-kD phosphoprotein has been detected in membrane fractions of both stimulated PMN and the cell-free oxidase system $(25,47,48)$. In a recent study the kinetics of appearance of the phosphoprotein in cytosol and membrane fractions were compatible with movement of the phosphorylated species from cytosol to membrane (50). The identity of the $47-\mathrm{kD}$ protein recognized by B-1 antiserum with a stimulus-dependent membrane-associated phosphoprotein in the cell-free oxidase system is supported by our analyses by two-dimensional gel electrophoresis (51) and by the presence of several potential phosphorylation sites in the predicted amino acid sequence of p47 $(28,29,31,32)$. If this is the case then obviously the defective phosphorylation in autosomal cytochrome $b$-positive CGD cells is due to absence of the $47-\mathrm{kD}$ substrate. In addition, failure to detect a stimulus-dependent $47-\mathrm{kD}$ phosphoprotein in membrane fractions of X-linked cytochrome 
$b$-negative CGD cells (50) raises the interesting possibility that cytochrome $b$ serves as the site for membrane association of the translocated $47-\mathrm{kD}$ cytosolic oxidase component.

The biochemical basis for membrane association remains a matter of speculation at this time. Phosphorylation of the 47-kD protein may constitute the signal for translocation, for example by neutralizing the strong positive charge in the carboxy-terminal domain $(31,32)$. A role for guanine nucleotides is suggested by the enhancement of oxidase activation by GTP analogues and inhibition by GDP analogues in the cell-free system $(23,33,52-54)$ and by the affinity of both p47 and p67 for GTP (23). Thus the binding of guanine nucleotides to one or both proteins may serve to regulate oxidase activation events (e.g., translocation) in a manner analogous to the functional roles of classical $G$ proteins. Finally, membrane association might be facilitated by acylation of the proteins, for example, by myristic acid. It is of interest that the macrophage, a myeloid cell with many features in common with the PMN, exhibits inducible myristoylation of proteins with relative molecular masses of $48 \mathrm{kD}(55)$ and $68 \mathrm{kD}(56)$. The amino-terminal glycine present in $\mathrm{p} 47(28,29,31,32)$ is a potential site for myristoylation.

In summary, we have shown that the $47-$ and $67-\mathrm{kD}$ cytosolic components of the human neutrophil NADPH oxidase system translocate to the plasma membrane in association with cell stimulation and oxidase activation. The data suggest that this translocation event is important in the assembly and activation of the oxidase system. It remains to be determined how cofactors such as $\mathbf{M g}^{2+}(13,15,52)$, ATP $(13,53)$, and GTP $(23,33,52-54)$ influence translocation, which membrane components serve as docking sites for the cytosolic proteins, and what the precise functional roles of the translocated proteins may be.

\section{Acknowledgments}

We thank Sherry Flanagan for preparation of the manuscript and Dr. P. G. Heyworth, Scripps Clinic, LaJolla, CA for providing a preprint of reference 50.

This work was supported by grants from the National Institutes of Health (AI-20866, AI-28412, and HL-34327) and the Department of Veterans Affairs. Dr. Clark is a Veterans Administration Medical Investigator, Dr. Volpp is supported by National Institutes of Health Physician Scientist Award DK-01295, and Dr. Nauseef is a Veterans Administration Clinical Investigator.

\section{References}

1. Klebanoff, S. J., and R. A. Clark. 1978. The Neutrophil: Functions and Clinical Disorders. Elsevier/North Holland, Amsterdam. $810 \mathrm{pp}$.

2. Lehrer, R. I., T. Ganz, M. E. Selsted, B. M. Babior, and J. T. Curnutte. 1988. Neutrophils and host defense. Ann. Intern. Med. 109:127-142.

3. Malech, H. L., and J. I. Gallin. 1987. Neutrophils in human diseases. N. Engl. J. Med. 317:687-694.

4. Babior, B. M. 1987. The respiratory burst oxidase. Trends Biochem. Sci. 12:241-243.

5. Bellavite, $P$. 1988. The superoxide-forming enzymatic system of phagocytes. Free Radicals Biol. Med. 4:225-261.

6. Tauber, A. I., N. Borregaard, E. Simons, and J. Wright. 1983. Chronic granulomatous disease: a syndrome of phagocyte oxidase deficiencies. Medicine (Baltimore). 62:286-309.

7. Segal, A. W. 1988. The molecular and cellular pathology of chronic granulomatous disease. Eur. J. Clin. Invest. 18:433-443.
8. Babior, B. M. 1988. The respiratory burst oxidase. Hematol. Oncol. Clin. N. Am. 2:201-212.

9. Curnutte, J. T. 1988. Classification of chronic granulomatous disease. Hematol. Oncol. Clin. N. Am. 2:241-252.

10. Curnutte, J. T. 1985. Activation of human neutrophil nicotinamide adenine dinucleotide phosphate, reduced (triphosphopyridine nucleotide, reduced) oxidase by arachidonic acid in a cell-free system. J. Clin. Invest. 75:1740-1743.

11. McPhail, L. C., P. S. Shirley, C. C. Clayton, and R. Snyderman. 1985. Activation of the respiratory burst enzyme from human neutrophils in a cell-free system: evidence for a soluble cofactor. J. Clin. Invest. 75:1735-1739.

12. Bromberg, Y., and E. Pick. 1985. Activation of NADPH-dependent superoxide production in a cell-free system by sodium dodecyl sulfate. J. Biol. Chem. 260:13539-13545.

13. Clark, R. A., K. G. Leidal, D. W. Pearson, and W. M. Nauseef. 1987. NADPH oxidase of human neutrophils: subcellular localization and characterization of an arachidonate-activatable superoxide-generating system. J. Biol. Chem. 262:4065-4074.

14. Curnutte, J. T., R. Kuver, and P. J. Scott. 1987. Activation of neutrophil NADPH oxidase in a cell-free system: partial purification of components and characterization of the activation process. J. Biol. Chem. 262:5563-5569.

15. Babior, B. M., R. Kuver, and J. T. Curnutte. 1988. Kinetics of activation of the respiratory burst oxidase in a fully soluble system from human neutrophils. J. Biol. Chem. 263:1713-1718.

16. Parkos, C. A., R. A. Allen, C. G. Cochrane, and A. J. Jesaitis. 1987. Putified cytochrome $b$ from human granulocyte plasma membrane is comprised of two polypeptides with relative molecular weights of 91,000 and 22,000. J. Clin. Invest. 80:732-742.

17. Parkos, C. A., M. C. Dinauer, L. E. Walker, R. A. Allen, A. J. Jesaitis, and S. H. Orkin. 1988. Primary structure and unique expression of the 22-kilodalton light chain of human neutrophil cytochrome b. Proc: Natl. Acad. Sci. USA. 85:3319-3323.

18. Parkos, C. A., R. A. Allen, C. G. Cochrane, and A. J. Jesaitis. 1988. The quarternary structure of the plasma membrane b-type cytochrome of human granulocytes. Biochim. Biophys. Acta. 932:71-83.

19. Royer-Pokora, B., L. M. Kunkel, A. P. Monaco, S. C. Groff, P. E. Newburger, R. L. Baehner, F. S. Cole, J. T. Curnutte, and S. H. Orkin. 1986. Cloning the gene for an inherited human disorderchronic granulomatous disease-on the basis of its chromosomal location. Nature (Lond.). 322:32-38.

20. Segal, A. W. 1987. Absence of both cytochrome b-245 subunits from neutrophils in X-linked chronic granulomatous disease. Nature (Lond.). 326:88-91.

21. Dinauer, M. C., S. H. Orkin, R. Brown, A. J. Jesaitis, and C. A. Parkos. 1987. The glycoprotein encoded by the X-linked chronic granulomatous disease locus is a component of the neutrophil cytochrome b complex. Nature (Lond.). 327:717-720.

22. Teahan, C., P. Rowe, P. Parker, N. Totty, and A. W. Segal. 1987. The $X$-linked chronic granulomatous disease gene codes for the $\beta$-chain of cytochrome b-245. Nature (Lond.). 327:720-721.

23. Volpp, B. D., W. M. Nauseef, and R. A. Clark. 1988. Two cytosolic neutrophil oxidase components absent in autosomal chronic granulomatous disease. Science (Wash. DC). 242:1295-1297.

24. Curnutte, J. T., R. L. Berkow, R. L. Roberts, S. B. Shurin, and P. J. Scott. 1988. Chronic granulomatous disease due to a defect in the cytosol factor required for nicotinamide adenine dinucleotide phosphate oxidase activation. J. Clin. Invest. 81:606-610.

25. Caldwell, S. E., C. E. McCall, C. L. Hendricks, P. A. Leone, D. A. Bass, and L. C. McPhail. 1988. Coregulation of NADPH oxidase activation and phosphorylation of a 48-kD protein(s) by a cytosolic factor defective in autosomal recessive chronic granulomatous disease. J. Clin. Invest. 81:1485-1496.

26. Nunoi, H., D. Rotrosen, J. I. Gallin, and H. L. Malech. 1988. Two forms of autosomal chronic granulomatous disease lack distinct neutrophil cytosol factors. Science (Wash. DC). 242:1298-1301. 
27. Clark, R. A., H. L. Malech, J. I. Gallin, H. Nunoi, B. D. Volpp, D. W. Pearson, W. M. Nauseef, and J. T. Curnutte. 1989. Genetic variants of chronic granulomatous disease: prevalence of deficiencies of two cytosolic components of the NADPH oxidase system. $N$. Engl. J. Med. 321:647-652.

28. Volpp, B. D., W. M. Nauseef, and R. A. Clark. 1989. Cloning of the cytosolic components of the neutrophil NADPH oxidase. Clin. Res. 37:567A. (Abstr.)

29. Lomax, K. J., T. L. Leto, N. Nunoi, J. I. Gallin, and H. L. Malech. 1989. Molecular cloning of a cDNA encoding a basic $47 \mathrm{kD}$ cytosolic factor deficient in the predominant form of autosomal recessive chronic granulomatous disease. Clin. Res. 37:547A. (Abstr.)

30. Leto, T. L., K. J. Lomax, J. M. G. Sechler, H. Nunoi, J. I. Gallin, and H. L. Malech. 1989. Molecular cloning of the $65 \mathrm{kD}$ cytosolic factor absent in a rare form of autosomal recessive chronic granulomatous disease. Clin. Res. 37:547A. (Abstr.)

31. Lomax, K. J., T. L. Leto, H. Nunoi, J. I. Gallin, and H. L. Malech. 1989. Recombinant 47-kilodalton cytosol factor restores NADPH oxidase in chronic granulomatous disease. Science (Wash. DC). 245:409-412.

32. Volpp, B. D., W. M. Nauseef, J. E. Donelson, D. R. Moser, and R. A. Clark. 1989. Cloning of the cDNA and functional expression of the 47 kilodalton cytosolic component of the human neutrophil respiratory burst oxidase. Proc. Natl. Acad. Sci. USA. 86:7195-7199.

33. Doussiere, J., M.-C. Pilloud, and P. V. Vignais. 1988. Activation of bovine neutrophil oxidase in a cell free system. GTP-dependent formation of a complex between a cytosolic factor and a membrane protein. Biochem. Biophys. Res. Commun. 152:993-1001.

34. Borregaard, N., J. M. Heiple, E. R. Simons, and R. A. Clark. 1983. Subcellular localization of the b-cytochrome component of the human neutrophil microbicidal oxidase: translocation during activation. J. Cell Biol. 97:52-61.

35. Petreccia, D. C., W. M. Nauseef, and R. A. Clark. 1987. Respiratory burst of normal human eosinophils. J. Leukocyte Biol. 41:283288.

36. Akard, L. P., D. English, and T. G. Gabig. 1988. Rapid deactivation of NADPH oxidase in neutrophils: continuous replacement by newly activated enzyme sustains the respiratory burst. Blood. 72:322327.

37. Cohen, H. J., and M. E. Chovaniec. 1978. Superoxide production by digitonin-stimulated guinea pig granulocytes: the effects of $N$-ethyl maleimide, divalent cations, and glycolytic and mitochondrial inhibitors on the activation of the superoxide generating system. $J$. Clin. Invest. 61:1088-1096.

38. Martin, M. A., W. M. Nauseef, and R. A. Clark. 1988. Depolarization blunts the oxidative burst of human neutrophils: parallel effects of monoclonal antibodies, depolarizing buffers, and glycolytic inhibitors. J. Immunol. 140:3928-3935.

39. Nauseef, W. M., J. A. Metcalf, and R. K. Root. 1983. Role of myeloperoxidase in the respiratory burst of human neutrophils. Blood. 61:483-491.

40. Clark, R. A., and W. M. Nauseef. 1988. Phagocyte oxidants and protective mechanisms. In Cellular Antioxidant Defense Mechanisms. Volume II. C. K. Chow, editor. CRC Press, Inc., Boca Raton, FL. 149-161.

41. Whitin, J. C., and H. J. Cohen. 1988. Disorders of respiratory burst termination. Hematol. Oncol. Clin. N. Am. 2:289-299.

42. Sha'ag, D., and E. Pick. 1988. Macrophage-derived superox- ide-generating NADPH oxidase in an amphiphile-activated cell-free system: partial purification of the cytosolic component and evidence that it may contain the NADPH binding site. Biochim. Biophys. Acta. 952:213-219.

43. Markert, M., G. A. Glass, and B. M. Babior. 1985. Respiratory burst oxidase from human neutrophils: Purification and some properties. Proc. Natl. Acad. Sci. USA. 82:3144-3148.

44. Kakinuma, K., Y. Fukuhara, and M. Kaneda. 1987. The respiratory burst oxidase of neutrổphils: separation of an FAD enzyme and its characterization. J. Biol. Chem. 262:12316-12322.

45. Umei, T., K. Takeshige, and S. Minikami. 1986. NADPH binding component of neutrophil superoxide-generating oxidase. $J$. Biol. Chem. 261:5229-5232.

46. Smith, R. M., J. T. Curnutte, and B. M. Babior. 1989. Affinity labeling of the cytosolic and membrane components of the respiratory burst oxidase by the 2',3'-dialdehyde derivative of NADPH. J. Biol. Chem. 264:1958-1962.

47. Segal, A. W., P. G. Heyworth, S. Cockroft, and M. M. Barrowman. 1985. Stimulated neutrophils from patients with autosomal recessive chronic granulomatous disease fail to phosphorylate a $M_{\mathrm{r}}-44,000$ protein. Nature (Lond.). 316:547-549.

48. Kramer, I. M., A. J. Verhoeven, R. L. van der Bend, R. S. Weening, and D. Roos. 1988. Purified protein kinase $C$ phosphorylates a 47-kDa protein in control neutrophil cytoplasts but not in neutrophil cytoplasts from patients with the autosomal form of chronic granulomatous disease. J. Biol. Chem. 263:2352-2357.

49. Okamura, N., J. T. Curnutte, R. L. Roberts, and B. M. Babior. 1988. Relationship of protein phosphorylation to the activation of the respiratory burst in human neutrophils: defects in the phosphorylation of a group of closely related 48-kDa proteins in two forms of chronic granulomatous disease. J. Biol. Chem. 263:6777-6782.

50. Heyworth, P. G., C. F. Shrimpton, and A. W. Segal. 1989. Localization of the $47 \mathrm{kDa}$ phosphoprotein involved in the respiratory-burst NADPH oxidase of phagocytic cells. Biochem. J. 260:243248.

51. Nauseef, W. M., B. D. Volpp, and R. A. Clark. 1989. Phosphorylation of a cytosolic component of the NADPH oxidase of human neutrophils. Eur. J. Clin. Invest. 19:A55. (Abstr.)

52. Gabig, T. G., D. English, L. P. Akard, and M. J. Schell. 1987. Regulation of neutrophil NADPH oxidase activation in a cell-free system by guanine nucleotides and fluoride: evidence for participation of a pertussis and cholera toxin-insensitive G protein. J. Biol. Chem. 262:1685-1690.

53. Seifert, R., and G. Schultz. 1987. Fatty-acid-induced activation of NADPH oxidase in plasma membranes of human neutrophils depends on neutrophil cytosol and is potentiated by stable guanine nucleotides. Eur. J. Biochem. 162:563-569.

54. Clark, R. A., B. D. Volpp, K. G. Leidal, and W. M. Nauseef. 1987. NADPH oxidase in subcellular fractions of human neutrophils: Evidence for a guanine and adenine nucleotide-dependent activation event. Clin. Res. 35:655A. (Abstr.)

55. Aderem, A. A., D. E. Marratta, and Z. A. Cohn. 1988. Interferon $\gamma$ induces the myristoylation of a $48-\mathrm{kDa}$ protein in macrophages. Proc. Natl. Acad. Sci. USA. 85:6310-6313.

56. Aderem, A. A., K. A. Albert, M. M. Keum, J. K. T. Wang, P. Greengard, and Z. A. Cohn. 1988. Stimulus-dependent myristoylation of a major substrate for protein kinase C. Nature (Lond.). 332:362364. 